\title{
Reflexões de estudantes de enfermagem sobre morte e o morrer
}

\author{
NURSING STUDENTS'REFLECTIONS ON DEATHAND DYING \\ REFLEXIONES DE LOS ESTUDIANTES DE ENFERMERÍA SOBRE LA MUERTE Y EL MORIR
}

\author{
José Roberto da Silva Brêtas', José Rodrigo de Oliveira², Lie Yamaguti ${ }^{3}$
}

\section{RESUMO}

Trata-se da apresentação da primeira fase de uma pesquisa sobre as representações de estudantes de enfermagem sobre a morte e o morrer. A mesma tem caráter exploratório e foi realizada junto a estudantes do primeiro ano do curso de graduação em Enfermagem da Universidade Federal de São Paulo. Teve por objetivos conhecer as impressões dos estudantes acerca do assunto "morte e o morrer" e subsidiar a segunda fase da pesquisa. Foi realizada por meio de uma dinâmica com uma questão norteadora, junto ao programa da disciplina curricular Psicologia Aplicada à Saúde. Para interpretação dos dados foi utilizado o método da Análise de Conteúdo, obtendo as seguintes categorias: medo da morte; conceitos; atitude diante da morte e o morrer; crença enquanto elemento interveniente.

\section{DESCRITORES}

Estudantes de enfermagem.

Morte.

Tanatologia.

\section{ABSTRACT}

This article refers to the first phase of a survey on nursing students' representations on death and dying. The research has an exploratory character and was carried out with first year students of the undergraduate course in Nursing of the Federal University of São Paulo. Its objectives were to know the impressions of the students concerning the theme "death and dying" and to give subsidies for the second phase of the survey. It was carried through a dynamic with a guiding question, as part of the curricular program of the discipline Psychology Applied to Health. For the interpretation of the data the method of the Analysis of Content was used, and the following categories were obtained: fear of death; concepts; attitude in the face of death and dying; belief as an intervening element.

\section{KEY WORDS}

Students, nursing.

Death.

Thanatology.

\section{RESUMEN}

Se trata de la presentación de la primera fase de una investigación sobre las representaciones de estudiantes de enfermería respecto a la muerte y al morir. La misma tiene carácter exploratorio y fue realizada con estudiantes del primer año del pregrado en Enfermería de la Universidad Federal de São Paulo. Tuvo por objetivos conocer las impresiones de los estudiantes acerca del asunto "muerte y morir" y subsidiar la segunda fase de la investigación. Fue realizada por medio de una dinámica con una pregunta orientadora, en la disciplina curricular Psicología Aplicada a la Salud. Para la interpretación de los datos fue utilizado el método del Análisis de Contenido, obteniendo las siguientes categorías: miedo a la muerte; conceptos; actitud frente a la muerte y el morir; creencia en cuanto elemento de intervención.

\section{DESCRIPTORES}

Estudiantes de enfermería.

Muerte.

Tanatología.
1 Enfermeiro,

Psicólogo, Doutor em Enfermagem/

UNIFESP, Professor

Adjunto da Univer-

sidade Federal de

robertobretas@

2 Graduando em

Enfermagem da

Universidade

Paulo. Bolsista do

$\mathrm{PIBIC/CNPq}$

yahoo.com.br

Enfermagem da

Universidade

Federal de São

Paulo - UNIFESP;

Polsista do Programa de Monitoria/

yamagutilie@

yahoo.com.br 


\section{INTRODUÇÃO}

A morte é um evento biológico que encerra uma vida. Nenhum outro evento vital é capaz de suscitar, nos seres humanos, mais pensamentos dirigidos pela emoção e reações emocionais que ela, seja no indivíduo que está morrendo, seja naqueles à sua volta ${ }^{(1)}$. $\mathrm{O}$ conceito tradicional de morte biológica definida como o instante do cessamento dos batimentos cardíacos tornou-se obsoleto. Hoje, ela é vista como um processo, como um fenômeno progressivo e não mais como um momento, ou evento. A revisão do conceito de morte, definindo-a como morte encefálica, tornouse necessária devido a diversos fatores, entre o quais se destaca: a capacidade da medicina de prolongar indefinidamente uma vida por meios artificiais; motivos sociais, humanos e mesmo econômicos; e o fato de as cirurgias de transplantes exigirem órgãos em perfeitas condições de vitalidade, para o seu sucesso ${ }^{(2-4)}$.

A morte não é somente um fato biológico, mas um processo construído socialmente, que não se distingue das outras dimensões do universo das relações sociais ${ }^{(5)}$. Assim, a morte está presente em nosso cotidiano e, independente de suas causas ou formas, seu grande palco continua sendo os hospitais e instituições de saúde.

Diante deste contexto, podemos afirmar que a morte é o destino certo de todos os seres vivos. No entanto só o ser humano pode ter consciência da própria morte, mas poucos falam dela, a maioria procura fugir do assunto.

É angustiante ao ser humano tomar consciência de sua finitude, visto que celebra cotidianamente a vida, sem pensar a morte. Trata-se de uma angústia metafísica, registrada na história da humanidade, desde os primórdios da civilização, representada principalmente pelo culto aos mortos, a crença na imortalidade, na vida depois da morte, o que simboliza a recusa da própria destruição e o anseio de eternidade (como exemplo tem-se a cultura do antigo Egito) ${ }^{(6)}$.

A morte enquanto final da existência humana é antecedida por diversas formas de morte que fazem parte do próprio desenvolvimento humano, como o próprio nascimento, que é a primeira morte no sentido da primeira perda, da primeira ruptura, da primeira separação, caracterizada pelo rompimento do cordão umbilical, é o fim da simbiose do feto com o útero materno (de uma convivência de nove meses, em um ambiente acolhedor, de holding) e de repente ocorre a substituição deste pelo meio externo. Depois a descoberta de si em detrimento da (o) outra (o) (com função materna), quando ocorre o fim da simbiose mãe/ bebê. Outro momento é a perda do corpo infantil e dos pais da infância durante o período da adolescência, culminando com a perda da juventude na terceira idade.
Em outras culturas, no mundo tribal, por exemplo, a morte não é propriamente um problema. Ela não é enfocada do ponto de vista da morte de um indivíduo, de forma isolada, mas se acha integrada nas práticas coletivas de culto aos mortos, aos ancestrais. O homem primitivo se acha de tal forma envolvido em sua comunidade que o seu ser, não tendo o centro em si mesmo, se faz por meio da participação no todo coletivo. Como a individualidade se encontra envolvida pela totalidade maior da comunidade, a morte não é percebida como dissolução, mas apenas como o assumir uma forma diferente da existência: o morto muda de estado e passa a pertencer à comunidade dos mortos. Para que este fato ocorra é necessário à realização de ritos de passagem que são adequados à situação ${ }^{(6)}$.

Nesta forma de ver a morte não existe a idéia de aniquilamento, os mortos podem retornar ao mundo dos vivos de outras formas, durante o sono destes e por meio de aparições. Enquanto que nas sociedades industrializadas atuais, ocorre um fenômeno diferente, onde a grande cidade cosmopolita destruiu os antigos laços comunitários (como a vida no interior onde muitas vezes o moribundo morria entre os seus), o que predomina é o individualismo, e a pessoa mesmo na hora de morrer está cada vez mais só(7).

As pessoas vivem num ritmo acelerado que é promovido pelo sistema de produção e não tem tempo para os velhos e os doentes. Os mesmos são tratados em ambientes assépticos e com técnicas cada vez mais sofisticadas que prolongam a vida, por outro lado não escapam à solidão e à impessoalidade do atendimento. Os enfermeiros e médicos são eficientes, mas o moribundo se encontra às vezes afastado da mão amiga, da atenção sem pressa nem profissionalismo $^{(8)}$.

A morte incomoda e desafia a onipotência humana e profissional, pois os profissionais da área da saúde são ensinados a cuidar da vida, mas não da morte. Prova deste fato é que na maior parte dos cursos de formação de profissionais da saúde, não existe uma disciplina curricular que trate do assunto de forma não defensiva e biologicista. Abrindo espaço para discussão das subjetividades. Quantas vezes ouvimos na enfermagem a frase não chore, você não pode chorar, nem demonstrar seus sentimentos na frente do paciente, se for seguir tais afirmações, talvez os tipos com personalidade adequada à função seriam os psicopatas e os sádicos.

Motivados pelo contexto apresentado, elaboramos uma pesquisa com bolsa do Programa de Iniciação Científica do $\mathrm{CNPq}$ sobre o assunto, junto aos estudantes do curso de graduação em enfermagem da Universidade Federal de São Paulo. Para tanto, elaboramos um projeto de pesquisa em duas fases, a primeira com caráter exploratório. A segunda, com maior abrangência, envolvendo todas as séries do cur- 
so de Enfermagem, intitulada Representações de estudantes de enfermagem sobre a morte e o morrer. E após a conclusão da primeira fase da pesquisa, apresentamos os resultados obtidos no presente trabalho.

\section{OBJETIVOS}

Este estudo tem por objetivos conhecer as impressões dos estudantes do primeiro ano do curso de graduação em Enfermagem da UNIFESP acerca do assunto morte e o morrer; servir de pesquisa exploratória para subsidiar a segunda fase da pesquisa.

\section{PERCURSO METODOLÓGICO}

Trata-se de um estudo com caráter exploratório-descritivo, em abordagem qualitativa, para o qual utilizamos o método da Análise de Conteúdo. A Análise de Conteúdo ${ }^{(9)}$ é um conjunto de técnicas de análise das comunicações. Onde esse conjunto de técnicas de análise das comunicações visa, através de procedimentos sistemáticos e objetivos de descrição do conteúdo das mensagens, obter indicadores, qualitativos ou não, que permitam a inferência de conhecimentos relativos às condições de produção/recepção dessas mensagens.

O projeto deste estudo foi avaliado e aprovado pelo Comitê de Ética da Universidade Federal de São Paulo, obedecendo aos requisitos estabelecidos pela Resolução 196/ 96, que trata das Normas de Pesquisa Envolvendo Seres Humanos ${ }^{(10)}$.

Os dados deste estudo foram coletados durante a realização de uma dinâmica em grupo, na qual utilizamos uma oficina enquanto instrumento, pelo fato de que a mesma possibilitou uma atmosfera de interação e reciprocidade entre os integrantes de cada grupo e os pesquisadores. Na medida em que houve um clima de estímulo e de aceitação mútua, as informações fluíram de maneira notável e autêntica.

O estudo foi desenvolvido no segundo semestre de 2002, junto a 71 estudantes do sexo feminino, matriculadas no primeiro ano do curso de graduação em Enfermagem da Universidade Federal de São Paulo, na disciplina curricular Psicologia Aplicada à Saúde. Para obtenção dos dados utilizamos como recurso uma oficina com atividade coletiva, tendo como tema central a questão norteadora: Representações da morte e o morrer.

Após a obtenção dos relatos de cada grupo sobre o tema proposto, utilizamos a técnica de Análise Categorial, em que realizamos a análise dos dados por meio de uma leitura integral dos relatos de cada grupo, tentando compreender o conhecimento acerca da temática. Lendo de tal forma a obter-se um sentido geral do todo de cada relato do grupo. Em seguida, realizamos uma releitura de cada relato, buscando identificar elementos estruturadores dos discursos proferidos pelos grupos sobre o assunto pesquisado, de forma que pudessem ser decompostos em categorias e subcategorias, proporcionando o eixo para análise dos mesmos.

\section{APRESENTAÇÃO DOS DADOS}

Com a análise dos dados, estruturamos os mesmos em categorias, buscando contornos do sistema de significação que, no seu conjunto revelaram as representações coletivas da morte e o morrer.

Partimos da sistematização de quatro categorias que representam o eixo em torno do qual o produto da dinâmica realizada se articula, a saber: medo da morte; conceitos; atitude diante da morte e o morrer; crença enquanto elemento interveniente.

Com relação à categoria medo da morte, identificamos as seguintes falas:

Medo de cemitério, aparição de uma pessoa conhecida.

Medo de ser enterrado vivo.

Medo do que irá acontecer após a morte.

A morte deve ser mais rápida, por que morrer afogada ou queimada deve ser mais sofrido.

O medo é saber se vai acabar a existência, se vou para outro estágio da morte, que poderia ser uma nova vida ou se tudo acabará.

Medo de esquecer o que foi vivido.

O maior medo não é o de morrer, mas sim da forma de morrer.

Eu tenho pavor da morte.

Alguns não tem medo de morrer, mas sim com vai ser, uma morte sofrida ou não.

Tenho medo do sofrimento que leva a morte.

Tenho medo de ficar sofrendo, de dar trabalho para os outros.

Eu não tenho medo da minha morte, nem de ninguém.

Não tenho medo da morte, acho que vou morrer cedo.

Eu queria morrer antes de todo mundo.

Não quero sentir nada quero morrer dormindo.

O medo da morte às vezes aparece por influência da família, que amedronta os filhos quanto ao pavor.

A essência da angústia humana é a extinção: o medo da morte, da destruição do eu e do próprio corpo. O homem é o único ser vivo que é consciente de sua morte e finitude, o que acarreta, então, a angústia de sua limitação, de nada poder fazer contra ela. A essência da motivação humana é a busca do significado para a vida, para o sofrimento e para a morte ${ }^{(11)}$. 
Quanto ao medo que as pessoas atribuem a morte, podemos admitir a concepção da morte sob dois aspectos, o medo da morte do outro e o medo da própria morte ${ }^{(12)}$.

O medo da morte começa a adquirir seus traços e o homem começa a formular planos para prolongar a vida, sobre o medo da morte coloca-se que medo é a resposta psicológica mais comum diante da morte ${ }^{(12)}$. O medo de morrer é universal e atinge todos os seres humanos, independente da idade, sexo, nível socioeconômico e credo religioso.

Com relação à morte do outro, observamos a existência do medo em ser abandonado, envolvendo a consciência da ausência e da separação.

A morte do outro se configura como a vivência da morte em vida. É a oportunidade de experiência da morte que não é a própria, mas é vivenciada como se uma parte de nós morresse (vínculos estabelecidos).

O medo da própria morte desvela a consciência da própria finitude, a fantasia de como será o fim e quando ocorrerá.

Com relação ao medo da própria morte, pode-se interpretálo como angústia da separação, que na eminência da separação da figura parental provoca ansiedade e estimula a pessoa ao impulso primitivo de apegar-se. O medo existencial, que se caracteriza pelo medo de deixar de ser encontra-se no fundo de cada pessoa de forma inconsciente, influenciando o comportamento das pessoas ao tomar consciência de sua situação de terminalidade. O medo da rejeição, em caso de doença que acarreta deformação, cheiro ruim ou mudança marcante de aparência, provoca comportamento de reclusão, tornando o indivíduo solitário e depressivo. O medo da dor, que é o mais comum de todos os medos, em que existe o temor da morte dolorosa. A perda do controle, no caso de enfermidades que possam acarretar a perda progressiva do controle sobre a própria vida, sendo mais assustador do que a perda de controle dos acontecimentos externos e das atividades dos outros é a perda do controle das funções corporais e mentais; é assistir a própria desintegração. $\mathrm{O}$ medo da morte súbita, que é caracterizado pelo acontecimento repentino (câncer disseminado). O medo da solidão, que é representado pelo temor de morrer sozinho, sem alguém para segurar na mão (sem acolhimento) ${ }^{(13)}$.

As situações que identificamos na categoria medo da morte revelam o medo e suas dimensões. Neste sentido, classifica-se o medo da morte em oito dimensões que são: medo de morrer, medo dos mortos, medo de ser destruído, medo da perda de pessoas significativas, medo do desconhecido, medo da morte consciente, medo do corpo após a morte e medo da morte prematura ${ }^{(12)}$.

O medo da morte provem da crença em uma destruição total entre os que não tem olhos a não ser para o sensível, enquanto que aquele que faz a experiência do pensamento, morrendo em seu corpo, descobre, nesse exercício, a imorta- lidade e o fato de que a alma não pode ser destruída ${ }^{(14)}$. A partir desta abordagem, salientamos a importância da reflexão sobre a morte enquanto fenômeno da vida.

Quanto à composição da categoria denominada conceitos, destacamos as seguintes frases:

A morte é a passagem para outra vida, uma continuidade.

Morte é separação e tristeza.

Morte é conseqüência da vida.

A morte é descanso.

Morte é dever cumprido.

Morte é punição.

Morrer é injusto.

As frases desvelam elementos de concepção espiritual, em que o indivíduo tem a morte enquanto transição entre o mundo material e o espiritual. A morte como transição é a representação das crenças e convicções espirituais do ser humano ${ }^{(15)}$.

Quanto à separação e tristeza, a perda de uma pessoa amada é uma das experiências mais intensamente dolorosa que o ser humano pode sofrer. É penosa não só para quem experimenta, como também para quem a observa, ainda pelo fato de sermos tão impotentes para ajudar ${ }^{(11)}$.

Outros compreendem a morte enquanto um processo natural relacionado ao desenvolvimento do ser humano.

A negação e o sentimento de injustiça também estão presentes, se negamos a morte, se nos recusamos a entrar em contato com nossos sentimentos, esse luto será mal elaborado, e teremos uma chance maior de adoecermos, cairmos em melancolia e em outros processos substutivos ${ }^{(16)}$.

As frases que denotam formas de encarar e enfrentar a morte e o morrer construíram a categoria que denominamos atitude diante da morte e o morrer, apresentada a seguir:

Nunca estamos preparados para enfrentar a morte é importante expressarmos tudo o que sentimos e dizer o que sentimos pelo outro.

Sinto muito a morte dos outros. Tenho dificuldade em lidar com o assunto.

Quanto mais velho a morte é mais aceitável.

É um acontecimento inevitável.

É difícil lidar com a separação e a perda.

O tempo é a melhor forma de se conformar e começar a pensar em momentos bons.

Os que ficam sofrem mais do que os que vão a maioria não lida muito bem com a morte, com a dor da saudade, com o inconformismo. Poucos percebem a naturalidade desse processo.

Até que ponto a universidade prepara o profissional para lidar com a morte? 
A grande dificuldade que foi exposta foi a maneira de dar a notícia de um óbito para familiares, pois como profissionais, temos que pensar no sofrimento dos que ficam, pois o possível foi feito para aquele que se foi.

Cada dia eu morro um pouco, tenho que deixar alguma coisa boa nas pessoas.

Devido aos problemas, nossa fuga é querer morrer.

Quero que meu corpo seja doado.

Nós estamos aqui para salvar a vida das pessoas.

Egoísmo de não querer ver os queridos morrerem, prefiro morrer primeiro.

Morrer de pouquinho em pouquinho para ir se despedindo devagar.

Dói ver os outros tristes.

O enfrentamento da morte tem por princípio o desenvolvimento da sua própria compreensão, tendo por dimensão os conceitos de irreversibilidade e universalidade, que aparece nas falas acima. A irreversibilidade refere-se à compreensão de que o corpo físico não pode viver depois da morte, portanto, inclui o reconhecimento da impossibilidade de mudar o curso biológico ou de retornar a um estado prévio. A universalidade refere-se a compreensão de que tudo que é vivo morre ${ }^{(17)}$

Muitos profissionais de saúde apresentam dificuldade em se relacionar com pacientes com prognóstico de morte e em fase terminal, isso se deve em parte às características apresentadas pelo paciente nessa fase e principalmente à dificuldade interna que sentem em lidar com o problema. Neste sentido, o profissional de enfermagem, em contato com esses diversos sentimentos vividos pelos pacientes e familiares pela aproximação da morte, está diante do conflito de como se posicionar frente ao sofrimento e a dor, que nem sempre pode aliviar, tendo também de elaborar perdas de pacientes, principalmente, daqueles com quem estabeleceu vínculos mais intensos ${ }^{(18)}$.

Muitos dos profissionais de enfermagem relatam que a proximidade da morte de um paciente no qual se dedicou horas de trabalho pode despertar sentimentos como impotência e culpa.

Neste sentido, a morte do doente pode trazer um certo alívio, mas, também, incitar sentimentos de culpa, pois a pessoa acredita que não tratou o outro da melhor forma possível e com isso não evitou a sua morte ${ }^{(12)}$.

Observamos também que aspectos relativos à faixa etária são determinantes no enfrentamento da morte e o morrer. Quanto a este fato, morte é percebida como mais traumatizante, quanto mais jovem for o paciente; muito mais traumatizante, ainda, em se tratando de crianças. No caso da pessoa idosa, a sua idade parece constituir-se em atenuante a tal percepção ${ }^{(19)}$.
Desvela-se a intenção de morrer antes do ente querido, para evitar a dor e o sofrimento da perda. Este fato pode revelar que a perda de um ente querido é uma experiência desconcertante e, algumas vezes, assustadora ${ }^{(13)}$.

No discurso dos estudantes emerge a preocupação com a formação profissional, em que o educar para o final da vida passa pela possibilidade de cada profissional de saúde envolvido neste processo, avaliar sua disponibilidade interna, seus valores, conceitos, preconceitos em relação à morte, ao morrer e também com relação as suas experiências pessoais de perdas, morte e luto ${ }^{(20)}$.

A Crença enquanto elemento interveniente revela a interferência da variável crença, uma convicção íntima em que a fé religiosa influencia na capacidade de enfrentamento de situações envolvendo a morte e o morrer, como podemos observar nas falas das estudantes:

Por acreditar que existe outro mundo além desse, a morte não é algo tão catastrófico.

É mais fácil encarar a morte pensando que é somente carnal, que o espírito continua.

Muitas pessoas aceitam a morte por não acreditarem que é o fim, acreditam que a morte é uma passagem, portanto, o espírito continua vivo; outros acreditam que na morte do corpo o espírito também morre.

Eu tenho uma certeza do que vai acontecer depois: alegria eterna.

Todas as religiões buscam explicações para o que acontece depois da morte.

Buscamos um conforto na religião para a dor da morte.

O conceito de morte e morrer é muito diferente de pessoa para pessoa, depende da história de vida, da religião e da fé de cada um.

A crença espiritual, a lembrança da convivência (momentos) aliada ao tempo, ajudam a confortar a dor da perda.

A morte como limite nos ajuda a crescer, mas a morte vivenciada como limite, também é dor, perda da função, do corpo, do afeto. O papel da religião é em parte o de socializar e dirigir os ritos de morte como forma de lidar com o terror $^{(12)}$.

A religião parece funcionar como um ansiolítico diante da morte e do morrer. Torna a morte um fato, de certa maneira, mais aceitável, por que inteligível e, portanto, explicáveis ${ }^{(21)}$.

\section{CONSIDERAÇÕES FINAIS}

O presente estudo possibilitou o conhecimento das impressões das estudantes do primeiro ano do curso de graduação em Enfermagem da UNIFESP acerca do assunto morte e o morrer. Através dessas impressões desvela- 
mos categorias que subsidiarão um estudo mais aprofundado sobre a temática junto a estudantes das outras séries do referido curso.

As categorias emergentes revelam que os sujeitos desta pesquisa apresentam vivências e experiências adquiridas junto à família e entorno, fato que caracteriza as estudantes da primeira série do curso, que ainda não iniciaram os estágios curriculares e conseqüentemente não tiveram nenhuma experiência com a morte no contexto de aprendizagem do cuidar profissional do outro.

Um dos aspectos emergentes dos relatos que chamou nossa atenção diz respeito ao enfrentamento da morte. Neste sentido, o processo de luto é a liberdade de expressar sentimentos que não eram ou não poderiam ser expressos sob circunstâncias de vida normais. Estar de luto pela morte dos outros é uma maneira de ensaiar a nossa morte. Mas o luto não é só isso; é também um ritual de expressão de alguns dos sentimentos mais profundos e íntimos da nossa existência.

Outro aspecto que destacamos é a preocupação das alunas com relação ao preparo para o enfrentamento das situações que envolvam experiências com a morte durante o curso de graduação em enfermagem. Neste sentido, concordamos com pesquisadores ${ }^{(22)}$, que atentam para carência de informações durante o período de formação da enfermeira no que se refere a este tema e recomendam experiências educacionais neste sentido.

A enfermagem tem como destaque a preocupação de seus profissionais em cuidar do paciente, o que envolve o olhar, a ausculta, a percepção e a disponibilidade para atender as necessidades dos pacientes sob seus cuidados ${ }^{(15)}$. O que sugere que estão mais preparados para atuar frente à doença e o processo de cura do que frente ao processo de morte e o morrer dos pacientes, e de luto de seus familiares ${ }^{(23)}$.

Durante o exercício da profissão, utilizando a ferramenta do cuidado, a enfermeira encara inúmeros sentimentos relacionados com o processo de morte e morrer, fica frente a frente com algo que não pode domar, quando a morte se torna presente emerge sentimentos de impotência, culpa, tristeza e medo. Neste processo de cuidar têm que assistir o morrer dos pacientes, o que acarreta frustração e provoca uma sensação de tristeza, lamentando a perda daquele alguém com quem se acostumara a conviver ${ }^{(24)}$.

Neste sentido, a enfermeira é a primeira profissional a lidar com a morte, a sentir a morte, uma vez que presta desde os mais simples aos mais complexos cuidados, principalmente quando o paciente se encontra em estágio final. Apesar da morte fazer parte das rotinas, todos desejam sempre que aconteça em outros plantões que não os seus. O sofrimento das pessoas da equipe de enfermagem se mascara pelo cumprimento de rotinas, a morte é uma evidência do nosso limite, da nossa mortalidade, da nossa condição humana ${ }^{(25)}$.
Desde o começar de sua formação, o estudante de enfermagem tem a idéia de que como profissional da saúde irá lutar tentando preservar a vida, em oposição com a possibilidade da morte.

A partir de sua formação, os profissionais vão se sentido compromissado com a vida, e é para a preservação desta que se sentem capacitados; sua formação acadêmica é fundamentada na cura e nela esta sua maior gratificação. Assim, quando em seu cotidiano de trabalho necessitam lidar com situações que envolvem a morte e o morrer, em geral sentemse despreparados e tendem a se afastar delas ${ }^{(26)}$.

Muitos autores afirmam que a dificuldade com que os profissionais de enfermagem têm em encarar a morte como um processo natural e aceitável se encontra nas raízes de sua formação.

É também relatado que mesmo junto aos alunos do curso de enfermagem e medicina, a discussão dessa temática não é freqüente no ensino teórico ou prático, mesmo quando esta situação significa uma realidade vivenciada quotidianamente em campo prático hospitalar ${ }^{(23)}$.

Coloca-se que há uma carência de informações durante o período de formação da enfermeira no que se refere a esse tema, a mesma autora relata que algumas iniciativas por parte de escolas de saúde têm procurado possibilitar algum preparo aos seus alunos com vistas a interferir na situação que vimos expondo, de modo que os futuros profissionais possam ser preparados para lidar com situações que envolvem a morte e o morrer ${ }^{(26)}$.

A dificuldade em falar sobre a morte e morrer durante a formação do estudante de enfermagem, impedindo o seu crescimento humano, pode emergir por parte dos professores, já que estes foram alunos e enfrentaram as mesmas dificuldades.

Também, o professor pode se sentir inseguro ao tratar o tema morte, daí sua impessoalidade, protegendo-se a si mesmo da dor, do sofrimento e da reflexão sobre sua própria finitude. Não propiciar oportunidade (espaço) ao aluno para refletir sobre a morte leva o professor a investir mais na técnica e a exigir do aluno um comportamento voltado, exclusivamente, para o material ${ }^{(27)}$.

Portanto, esse breve estudo, primeira fase de uma pesquisa, dá início a um trabalho de intervenção que desenvolver-se-á junto a estudantes do curso de graduação em Enfermagem da Universidade Federal de São Paulo, que futuramente será materializado na elaboração de uma disciplina eletiva. Entendemos que a criação desses espaços para sensibilização, autoconhecimento e reflexão sobre o tema da morte e do morrer num contexto universitário, especificamente dentro da graduação em Enfermagem, certamente é formar um profissional não só capacitado para assistir a vida com qualidade, mas também o processo de morte e o morrer. 


\section{REFERÊNCIAS}

(1) Lunardi Filho WD, Sulzbach RC, Nunes AC, Lunardi VL. Percepções e condutas dos profissionais de enfermagem frente ao processo de morte e morrer. Texto Contexto Enferm. 2001;10(3):60-81.

(2) Horta MP. Eutanásia: problemas éticos da morte e do morrer. Bioética. 1999;7(1):59-64.

(3) Grupo de Estúdios de Ética Clínica de la Sociedad Médica de Santiago. Diagnóstico de muerte. Revista Med Chile. 2004;132(1):95-107.

(4) Salum AMC, Cavalcanti ACV, Pedrolo AS. Morte encefálica: conhecimento necessário à formação do enfermeiro. Mundo Saúde. 1996;20(10):343-9.

(5) Menezes RA. Em busca da boa morte: antropologia dos cuidados paliativos. Rio de Janeiro: Editora Fiocruz; 2004.

(6) Ariès P. O homem diante da morte. Rio de Janeiro: Francisco Alves; 1981.

(7) Ariès P. História da morte no ocidente: da idade média aos nossos dias. Rio de Janeiro: Ediouro; 2003.

(8) Elias N. A solidão dos moribundos, seguido de envelhecer e morrer. Rio de Janeiro: Jorge Zahar; 2001.

(9) Bardin L. Análise de conteúdo. Lisboa: Edições 70; 1995.

(10) Conselho Nacional de Saúde. Comissão Nacional de Ética em Pesquisa. Manual operacional para Comitês de Ética em Pesquisa. Brasília; 2002.

(11) Bowlby J. Perda: tristeza e depressão. São Paulo: Martins Fontes; 1985

(12) Kovács MJ, Rothschild D, Morato HTP, Freitas LV, Cassorla RMS, Rosemberg RL, et al. Morte e desenvolvimento humano. São Paulo: Casa do Psicólogo; 2002.

(13) Stedford E. Encarando a morte: uma abordagem ao relacionamento com o paciente terminal. Porto Alegre: Artes Médicas; 1986.

(14) Dastur F. A morte: ensaio sobre a finitude. Rio de Janeiro: Bertrand; 2002
(15) Kovács MJ. Pensando a morte e a formação de profissionais de saúde. In: Cassorla RMS, Kovács MJ, Alves RA, Barbosa MAS, Télis CMT, Baggio HD, et al. Da morte: estudos brasileiros. Campinas: Papirus; 1991. p. 79-103.

(16) Cassorla RMS, Kovács MJ, Alves RA, Barbosa MAS, Télis CMT, Baggio HD, et al. Da morte: estudos brasileiros. Campinas: Papirus; 1991.

(17) Torres WCA. Criança diante da morte: desafios. São Paulo: Casa do Psicólogo; 1999.

(18) Kovács MJ. Educação para morte: desafio na formação de profissionais de saúde e educação. São Paulo: Casa do Psicólogo/FAPESP; 2003.

(19) Lunardi VL, Lunardi Filho WD. A morte do idoso: um fato natural e aceitável? Texto Contexto Enferm. 1997;6(2):322-9.

(20) Esslinger I. De quem é a vida, afinal? Descortinando os cenários da morte no hospital. São Paulo: Casa do Psicólogo; 2004.

(21) Silva ALL, Ruiz EM. Cuidar, morte e morrer: significações para profissionais de enfermagem. Est Psicol. 2003;20(1):15-25.

(22) Boemer MR, Varga EV, Mendes MR, Valle ERM. O tema da morte: uma proposta de educação. Rev Gaúcha Enferm. 1991;12(1):26-32.

(23) Gonçalves LHT, Schineider P. Enfermagem e o idoso hospitalizado em condição terminal. Acta Paul Enferm. 2001;14(1):72-81.

(24) Spindola T, Macedo MCS. A morte no hospital e seu significado para os profissionais. Rev Bras Enferm. 1994;47(2):108-17.

(25) Ribeiro MC, Baraldi S, Silva MJP. A percepção da equipe de enfermagem em situação de morte: ritual do preparo do corpo “pós-morte”. Rev Esc Enferm USP. 1998;32(2):117-23.

(26) Boemer MR, Rossi LRG, Nastari RR. A idéia de morte em Unidade de Terapia Intensiva: análise de depoimentos. In: Cassorla RMS, Kovács MJ, Alves RA, Barbosa MAS, Télis CMT, Baggio HD, et al. Da morte: estudos brasileiros. Campinas: Papirus; 1991. p. 145-57.

(27) Valsecchi EASS, Nogueira MS. Fundamentos de enfermagem: incidentes críticos relacionados à prestação de assistência em estágio supervisionado. Rev Lat Am Enferm. 2002;10(6):819-24. 